\title{
Pringle manoeuvre versus selective hepatic vascular exclusion: outcome of a case series in a tertiary referral centre
}

\author{
C N Wijesurendere, F H D S Silva, A A Pathirana, T Wijeratne
}

(Index words: Pringle manoeuvre, selective hepatic vascular exclusion, major hepatectomy, intra-operative blood loss)

\begin{abstract}
A retrospective comparative study was done to compare the outcome of intermittent Pringle manoeuvre (IPM) and selective hepatic vascular exclusion (SHVE) in 19 major hepatectomies in non-cirrhotic patients that were done from October 2003 to June 2009. Intra-operative blood loss (IBL), total operative time (TOT) and immediate outcome were assessed in the two groups. Thirteen underwent IPM and the others underwent SHVE. The mean age was 50 years (SHVE) and 39.2 years (IPM). Mean IBL was 641 $\mathrm{ml}$ and $802 \mathrm{ml}$ in the SHVE and IPM groups respectively $(p>.05)$. TOT was 4.7 hours in both groups. There was one mortality from myocardial infarction in the IPM group and no morbidities in both groups. The results obtained from this study shows that IPM is equivalent to SHVE, with regards to IBL, TOT and immediate outcome in major hepatectomies in non-cirrhotic patients.
\end{abstract}

Ceylon Medical Journal 2014; 59: 139-140

\section{Introduction}

Major hepatectomy is defined as resection of three or more anatomical segments of the liver [1]. Intra-operative blood loss (IBL) is an important factor which determines the outcome of major hepatic resections [2]. Main determinants of blood loss are the method of transection and vascular control. Many methods are available to achieve vascular control during transection of hepatic parenchyma. Of these, intermittent Pringle manoeuvre (IPM) and selective hepatic vascular exclusion (SHVE) are widely adopted. IPM is technically less demanding, therefore it can be performed by surgeons with limited experience in liver surgery. While some studies have shown SHVE to be superior, there are others which have not shown a difference in outcome [3 -6].

\section{Method}

A retrospective study was carried out at the University Surgical Unit, Colombo South Teaching
Hospital. Our unit database was used to retrieve data of all major hepatectomies in non-cirrhotic livers that were performed from October 2003 to June 2009. All patients were included in the study except those in the paediatric age group. They were divided into two groups IPM and SHVE, based on the method of inflow control which was used. SHVE was used in all patients from 2007 and IPM was the method of inflow control used until then. Since 2007, surgeons had taken a policy decision to use SHVE instead of IPM regardless of the pathology or the anticipated risk of bleeding. Both groups had an indication (benign or malignant) to undergo major hepatectomy and belonged to ASA groups 1 or 2. There were no acquired or inherited coagulopathy identified in both groups and all patients had normal liver function.

Intra-operative blood loss (IBL) was a measure of the total blood volume of all swabs and gauze towels soaked during surgery plus the volume of the suction reservoir minus the irrigated saline, at the end of surgery. IBL, total operative time (TOT) and immediate outcome were assessed and compared between the two groups. Data analysis was done using Statistical Package for Social Sciences (SPSS).

\section{Results}

A total of 19 patients underwent major hepatectomy within the given period. All surgeries were performed by consultant surgeons attached to the surgical unit. Hypotensive anaesthesia with low central venous pressure (below $5 \mathrm{~cm} \mathrm{H}_{2} \mathrm{O}$ ) was used in all surgeries. The indication for hepatic resection is shown in table1. Colorectal liver metastases was the commonest indication and was present in 9 patients (47\%). Parenchymal transection was done using Kelly clamp - crushing technique.

There was no statistically significant difference in TOT ( $p=>0.05)$ or IBL $(p=>0.05)$ (table 2$)$. There was one mortality in the IPM group, where a patient died from a myocardial infarction on post-operative day 2 . There were no morbidities in either group.

University Surgical Unit, Colombo South Teaching Hospital, Kalubowila, Sri Lanka.

Correspondence: CNW, e-mail: <chikadaman@yahoo.com>. Received 16 May 2014 and revised version accepted 30 August 2014. Competing interests: none declared. 
Table 1. Indication for hepatic resection

\begin{tabular}{lll}
\hline Indication for resection & $\begin{array}{l}\text { Selective } \\
\text { hepatic } \\
\text { vascular } \\
\text { exclusion }\end{array}$ & $\begin{array}{l}\text { Intermittent } \\
\text { Pringle } \\
\text { manoeuvre }\end{array}$ \\
\hline $\begin{array}{l}\text { Metastasis from colorectal } \\
\text { carcinoma }\end{array}$ & 3 & 6 \\
$\begin{array}{l}\text { Hepatocellular carcinoma } \\
\text { Metastasis from breast } \\
\text { carcinoma }\end{array}$ & 2 & 4 \\
Metastasis from ovarian \\
carcinoma
\end{tabular}

Table 2. Comparison of outcome of IPM and SHVE

\begin{tabular}{llll}
\hline & $\begin{array}{l}\text { Intermittent } \\
\text { Pringle } \\
\text { manoeuvre }\end{array}$ & $\begin{array}{l}\text { Selective } \\
\text { hepatic } \\
\text { vascular } \\
\text { exclusion }\end{array}$ & $\begin{array}{l}\text { Signif- } \\
\text { cance }\end{array}$ \\
& Mean (SD) & Mean (SD) & \\
\cline { 2 - 4 } & $39.2(16.3)$ & $50(13.8)$ & \\
\hline $\begin{array}{l}\text { Age (years) } \\
\text { Total operative }\end{array}$ & $4.69(1.09)$ & $4.75(1.17)$ & $\begin{array}{l}\mathrm{t}=0.105 \\
\text { time (hours) }\end{array}$ \\
$\begin{array}{l}\text { Intraoperative } \\
\text { blood loss (ml) }\end{array}$ & $641(450.4)$ & $802(497.4)$ & $\begin{array}{l}\mathrm{t}=0.7 \\
p=>0.05\end{array}$ \\
\hline
\end{tabular}

\section{Discussion}

Major hepatic resections are on the rise in the developing world due to the increase in treatment of many malignant and non malignant conditions of the liver with a curative intent. Of the malignant conditions, colorectal cancer metastases to the liver is the main indication for liver resection. Major hepatic resections has an overall morbidity of $20-30 \%$ and mortality of $4-5 \%$ [7].

IPM, which is clamping of hepatic inflow at the free edge of the lesser omentum is technically easier compared to SHVE which involves dissection and clamping of vascular inflow to either hemi-liver. IPM causes deterioration of liver function in cirrhosis [8]. SHVE can be safely used in cirrhotic livers but it may be technically demanding for surgeons with limited experience in hepatic surgery. Also the line of demarcation of the liver that appears in SHVE is a useful guide for parenchymal transection.

Despite several large retrospective and prospective studies carried out to assess the efficacy of IPM and SHVE, it is difficult to arrive at a conclusion as comparisons cannot be made due to wide variability of studies [3-6].

There are several limitations in this study. Firstly it is a retrospective study. SHVE was employed once the necessary competency was achieved. Therefore, the patients in the SHVE were recruited more recently. The growing experience and skills of the surgeon may have reduced IBL to some extent. The higher mean age of SHVE group is less likely to have affected IBL as this was unlikely to be a risk factor for bleeding among this group. Finally the differences in pathology and its vascularity was not taken into account in this study.

\section{Conclusion}

This study shows that vascular control achieved by IPM is equivalent to SHVE, with regards to IBL, TOT and immediate outcome in major hepatectomies. Therefore vascular control by Pringle manoeuvre which is technically easier, may be safely used for major hepatic resections in non-cirrhotic livers.

\section{References}

1. Sheung Tat Fan, Chung Mau Lo, Chi Leung Liu. Major hepatic resection for primary and metastatic tumors. In: Fischer, Josef E. Mastery of Surgery, 5th edition. Lippincott Williams \& Wilkins 2007; 1076-91.

2. Correa-Gallego C, Gonen M, Fischer M, et al. Perioperative complications influence recurrence and survival after resection of hepatic colorectal metastases. Annals of Surgical Oncology 2013; 20: 2477-84.

3. Lau WY, Lai EC, Lau SH. Methods of vascular control technique during liver resection: a comprehensive review. Hepatobiliary \& Pancreatic Diseases International 2010; 9: 473-81.

4. Zhang J, Lai EC, Zhou WP, et al. Selective hepatic vascular exclusion versus Pringle manoeuvre in liver resection for tumours encroaching on major hepatic veins. The British Journal of Surgery 2012; 99: 973-7.

5. Smyrniotis VE, Kostopanagiotou GG, Contis JC, et al. Selective hepatic vascular exclusion versus Pringle maneuvre in major liver resections: prospective study. World Journal of Surgery 2003; 27: 765-9.

6. Chau GY, Lui WY, King KL, Wu CW. Evaluation of effect of hemi hepatic vascular occlusion and Pringle maneuvre during hepatic resection for patients with hepatocellular carcinoma and impaired liver function. World Journal of Surgery 2005; 29: 1374-83.

7. Mastoraki A, Tsakali A, Papanikolaou IS, et al. Outcome following major hepatic resection in the elderly patients. Clinics and Research in Hepatology and Gastroenterology 2014; (in press)

8. Sugiyama Y, Ishizaki Y, Imamura $\mathrm{H}$, et al. Effects of intermittent Pringle's manoeuvre on cirrhotic compared with normal liver. The British Journal of Surgery 2010; 97: 1062-9. 